\section{Fatores associados ao consumo adequado de frutas e hortaliças em escolares de Santa Catarina, Brasil}

\author{
Factors associated with adequate fruit and \\ vegetable intake by schoolchildren in \\ Santa Catarina State, Brazil
}

\author{
1 Programa de Pós-graduação \\ em Nutrição, Universidade \\ Federal de Santa Catarina, \\ Florianópolis, Brasil. \\ 2 Universidade Federal do \\ Pará, Belém, Brasil. \\ Correspondência \\ L. C. F. Costa \\ Programa de Pós-graduação \\ em Nutrição, Universidade \\ Federal de Santa Catarina. \\ Campus Universitário \\ Trindade, Florianópolis, SC \\ 88040-970, Brasil. \\ larissafeio@yahoo.com.br
}

\section{Abstract}

This study aimed to estimate fruit and vegetable intake and identify associated factors among schoolchildren in Santa Catarina State, Brazil. A cross-sectional study was conducted with 4,964 students from public and private schools in eight districts in the State, analyzing socioeconomic and anthropometric data and dietary intake. Adequate fruit and vegetable intake was defined as five or more servings per day. Poisson regression was performed to test associations between fruit and vegetable intake and independent variables $(p<0.05)$. Adequate intake was found in $2.7 \%$ of children, while $26.6 \%$ of the sample did not consume any fruits and vegetables. In the analysis of the association between independent variables and adequate fruit and vegetable intake in the total sample, only geographic region (residents in western Santa Catarina) and consumption of candy were significantly associated. In the stratified analysis by sex, for boys, only geographic region was associated, while among girls, region and candy consumption were significantly associated with adequate fruit and vegetable intake. The findings indicate the need for specific strategies in the school community to improve fruit and vegetable intake by schoolchildren.

Food Consumption; School Feeding; Fruit; Vegetables
Larissa da Cunha Feio Costa 1,2

Francisco de Assis Guedes de Vasconcelos 1 Arlete Catarina Tittoni Corso 1

\section{Introdução}

Vários estudos epidemiológicos têm sugerido a importância do consumo de frutas e hortaliças na promoção da saúde e prevenção de doenças crônicas não transmissíveis, como doenças cardiovasculares, câncer, diabetes e obesidade 1,2,3. O conhecimento sobre o consumo desses alimentos considerados protetores torna-se essencial, uma vez que hábitos de vida estabelecidos na infância podem ser mantidos na vida adulta. Além disso, práticas alimentares inadequadas têm sido reconhecidas como um dos principais determinantes da obesidade 4 , cuja prevalência no Brasil, no decorrer de três décadas (19742008), triplicou entre crianças em idade escolar e adolescentes 5 .

Segundo recomendações da Organização Mundial da Saúde (OMS) e da Organização das Nações Unidas para Agricultura e Alimentação (FAO) 6, o consumo mínimo de frutas e hortaliças para adultos deve ser de $400 \mathrm{~g}$ por dia, recomendação também adotada pelo Ministério da Saúde do Brasil 7. Porém, de acordo com algumas investigações, a ingestão desses alimentos ainda é baixa no Brasil 8,9. A Pesquisa de Orçamentos Familiares (POF) 2008/2009 identificou consumo insuficiente de frutas e hortaliças $(<400 \mathrm{~g}$ diários) em mais de $90 \%$ da população brasileira ${ }^{8}$.

A Pesquisa Nacional de Saúde do Escolar (PeNSE) realizada em 2009, com 60.973 estudantes entre 13 e 15 anos de escolas públicas e 
privadas das capitais brasileiras, revelou que o consumo quase diário ( $\geq 5$ vezes na semana) de guloseimas $(50,9 \%)$ foi superior ao consumo de frutas frescas $(31,5 \%)$ em todas as cidades avaliadas. A PeNSE apontou, ainda, que as médias de consumo de frutas nas regiões Norte $(25,3 \%)$ e Nordeste (26\%) foram inferiores às das demais regiões, Centro-oeste (32,6\%), Sudeste (35,3\%) e Sul (31,9\%). No Município de Florianópolis, Santa Catarina, a média de consumo de frutas cinco ou mais vezes na semana foi de $34,1 \%$, enquanto a média de consumo de guloseimas foi de $43,6 \% 9$.

O consumo baixo desses alimentos também foi evidenciado por outros estudos de âmbito local realizados no país, em crianças e adolescentes 10,11. Toral et al. 10, investigando 234 escolares na faixa etária de 10-19 anos em escolas de ensino técnico de São Paulo, capital, encontraram mediana de consumo de porções diárias de frutas e verduras de 0,97 e 1,2, respectivamente. Estes autores constataram que $89 \%$ dos escolares ingeriam frutas e verduras abaixo do consumo estabelecido pelo Guia da Pirâmide Alimentar Brasileira 12 (4 a 5 porções de verduras e 3 a 5 de frutas). Nunes et al. 11, por sua vez, avaliaram 588 adolescentes de escolas públicas e privadas da cidade de Campina Grande, Paraíba, tendo verificado que o consumo diário de frutas foi de apenas $4,5 \%$, enquanto o de suco de frutas, de 18,8\%.

No Estado de Santa Catarina, as pesquisas sobre o consumo alimentar da população escolar são escassas, principalmente informações específicas a respeito do consumo de frutas e hortaliças. Os poucos estudos realizados concentraram informações da capital do estado, Florianópolis, tendo sido identificados dois trabalhos que avaliaram o consumo alimentar de escolares desta cidade. Na investigação realizada por Fiates et al. 13, $65,5 \%$ e $41,4 \%$ das meninas e $71,4 \%$ e $60,7 \%$ dos meninos relataram consumir, respectivamente, frutas e verduras de quatro a sete vezes na semana. Por sua vez, no estudo de Assis et al. 14, $15 \%$ dos escolares avaliados na capital encontravam-se com consumo adequado de frutas e hortaliças, segundo as recomendações do Guia Alimentar da População Brasileira 15 ( $\geq 5$ porções diárias).

Diante da escassez de pesquisas com escolares na região e da relevância deste tema, o presente estudo objetivou estimar a frequência e os fatores associados ao consumo adequado de frutas e hortaliças em escolares do Estado de Santa Catarina.

\section{Método}

\section{Tipo de estudo e amostra}

O estudo caracteriza-se como transversal. Os dados analisados são provenientes de projeto de pesquisa financiado pelo Conselho Nacional de Desenvolvimento Científico e Tecnológico (CNPq - processo $\mathrm{n}^{\circ}$. 402334/2005-1). O projeto objetivou acompanhar o processo de implementação da Lei de Regulamentação das Cantinas Escolares, relacionada aos hábitos alimentares e o estado nutricional de escolares do Ensino Fundamental em Santa Catarina. O Estado de Santa Catarina localiza-se na Região Sul do Brasil e, segundo dados do Censo Demográfico de 2010 (Instituto Brasileiro de Geografia e Estatística. http:/ / www.ibge.gov.br/censo2010/dados_divulgados/ index.php, acessado em 17/Abr/2011), conta com pouco mais de 6.178.603 de habitantes, dentre os quais 748.356 são estudantes escolares do Ensino Fundamental, e um território de 95.400 $\mathrm{km}^{2}$ (Governo do Estado de Santa Catarina. Santa Catarina: geografia - regiões. http://www.sc.gov. $\mathrm{br/conteudo/santacatarina/geografia/paginas/}$ regioes.htm, acessado em 24/Jul/2011).

Os procedimentos metodológicos do processo de definição do tamanho e seleção da amostra já foram descritos em artigos publicados por Ricardo et al. 16 e Gabriel et al. 17. Em síntese, ressalta-se que o plano de amostragem comportou duas unidades de análise de interesse: a escola e o escolar. Para compor o universo de escolas de Ensino Fundamental do Estado de Santa Catarina, estas foram distribuídas em três regiões: oeste (oeste e meio-oeste), centro (norte, serrana e Alto Vale) e litoral (grande Florianópolis, litoral norte e sul).

Nas três regiões geográficas, as escolas localizavam-se em oito municípios de referência, classificados como aqueles com o maior número de escolares matriculados nas séries iniciais do Ensino Fundamental: Chapecó e Joaçaba, no oeste; Blumenau, Jaraguá do Sul e Lages, no centro; Criciúma, Florianópolis e Joinville, no litoral.

De acordo com dados do Censo Educacional do Ministério da Educação, em 2006 havia 4.007 escolas de Ensino Fundamental no estado, sendo uma federal, 3.661 escolas públicas (municipais e estaduais) e 345 particulares (http:/ / www.inep. gov.br/censo/basica/dataescolabrasil/). Para o cálculo da amostra, foi excluída a escola federal e aquelas que declararam não ter escolares nas séries iniciais do Ensino Fundamental. Para a definição final das escolas a serem investigadas, foram introduzidos outros critérios fundamentados em questões financeiro-operacionais, como a dependência administrativa da escola 
(pública e particular) e o número de escolares matriculados.

Dessa forma, o universo de estudo foi composto por 140.878 escolares matriculados em 569 escolas públicas e particulares dos oito municípios selecionados anteriormente, separados em seis estratos de interesse, formados pela combinação das três regiões e de duas dependências administrativas. Ressalta-se que a amostra foi planejada de modo a garantir uma boa precisão para as estimativas dos parâmetros dos estratos de interesse relacionados com a unidade escola, em particular na estimativa de proporções.

O número de escolas investigado foi calculado de modo a garantir um erro amostral de no máximo seis pontos percentuais, para mais ou para menos, para cada um dos seis estratos de interesse (combinações das três regiões com as duas redes de dependência administrativa), supondo-se que as proporções a serem estimadas sejam menores ou iguais a 0,30 , ou maiores ou iguais a 0,70. Assim, a amostra final foi composta por 347 escolas, sendo 266 públicas e 81 particulares.

A seleção dos escolares foi feita de forma aleatória; uma classe (turma) de cada escola foi amostrada, fazendo com que o plano amostral fosse por conglomerado em dois estágios (primeiro a escola, depois o escolar). A amostra de escolares foi aleatória por partilha proporcional à série, sendo sorteada uma turma do segundo ao quinto ano em cada escola participante da amostra. Para o cálculo do número de escolares, estimou-se que, em cada uma das 347 escolas, fosse selecionada uma turma com aproximadamente 15 a 30 escolares, de ambos os sexos, matriculados entre a primeira e a quarta série do Ensino Fundamental de oito anos, ou entre o segundo e quinto ano do mesmo segmento de nove anos, estimando uma amostra de aproximadamente 5.205 a 10.410 escolares.

Ressalta-se, entretanto, que a amostra final resultou em 5.686 escolares, pois o número de alunos por turma foi menor que o esperado e houve aqueles que não retornaram o Termo de Consentimento Livre e Esclarecido assinado pelos responsáveis. Além disso, não foi possível realizar a coleta de dados em três escolas, totalizando em 344 pesquisadas (269 públicas e 75 particulares).

\section{Coleta de dados}

A coleta de dados foi realizada no período de junho de 2007 a maio de 2008, com escolares matriculados em escolas públicas e particulares de ensino fundamental, localizadas em oito municípios do Estado de Santa Catarina.
A equipe responsável pela coleta foi composta por nutricionistas e acadêmicos dos Cursos de Graduação e Pós-graduação em Nutrição da Universidade Federal de Santa Catarina (UFSC). A equipe foi treinada com base em um protocolo de padronização dos procedimentos de coleta de dados, previamente estabelecido, a fim de minimizar os possíveis erros intra e interavaliadores. Não foi determinado o erro técnico de medição entre a equipe de coleta, mas $10 \%$ da amostra dos escolares foi medida em duplicata para o controle da qualidade das medidas antropométricas.

\section{Variáveis independentes}

As variáveis independentes foram sexo (masculino e feminino); idade ( $\leq 8$ anos e $>8$ anos); região (oeste, centro e litoral); dependência administrativa (pública e privada); escolaridade dos pais $(\leq$ 8 anos de estudo e $>8$ anos de estudo); estado nutricional do escolares segundo o IMC (eutrofia e excesso de peso); consumo de guloseimas $(\leq 2$ vezes ao dia e $>2$ vezes ao dia); horas de TV durante a semana e horas de computador e/ ou videogame durante a semana ( $\leq 2$ horas e $>2$ horas).

Dados referentes à região, dependência administrativa da escola, idade e sexo dos alunos foram obtidos na secretaria das escolas e repassados para uma ficha de identificação do escolar. Dados referentes à escolaridade dos pais e tempo de exposição dos escolares à TV e ao computador e/ou videogame foram obtidos por meio de questionário a ser preenchido pelos próprios pais ou responsáveis pela criança, enviado junto com o Termo de Consentimento Livre e Esclarecido.

Os dados antropométricos de peso e estatura dos escolares foram coletados de acordo com procedimentos descritos no Anthropometric Standardization Reference Manual de Lohman et al. 18. A medida de peso foi obtida em tomada única, com uso de balança digital, da marca Marte, modelo PP 180 (Santa Rita do Sapucaí, Brasil), com capacidade para $180 \mathrm{~kg}$ e precisão de 100g. Para a obtenção da medida de estatura, foi utilizado o estadiômetro de fabricação Alturexata, com precisão de $1 \mathrm{~mm}$ (Belo Horizonte, Brasil), em tomada única. As medidas de peso e estatura foram utilizadas para o cálculo do índice de massa corporal (IMC), em que o peso em quilogramas foi dividido pelo quadrado da estatura em metros.

A classificação do estado nutricional dos escolares foi realizada de acordo com o IMC por sexo e idade, segundo os pontos de corte propostos por Cole et al. 19, recomendado pela International Obesity Task Force (IOTF). O IMC foi agrupado em excesso de peso (sobrepeso e obesidade, IMC $\geq$ $25 \mathrm{~kg} / \mathrm{m}^{2}$ ) e eutrofia $\left(\mathrm{IMC}<25 \mathrm{~kg} / \mathrm{m}^{2}\right)$. 
Para a obtenção dos dados de consumo alimentar, foi utilizada a versão 3 do Questionário Alimentar do Dia Anterior (QUADA) - instrumento desenvolvido e validado por Assis et al. 20,21, Barros et al. 22, Lobo et al. ${ }^{23}$. Os resultados da validação mostraram parâmetros de alta sensibilidade, com valores variando entre $73,4 \%$ (feijão) e $95,5 \%$ (arroz), e alta especificidade, variando entre $87,3 \%$ (frutas) e $98,8 \%$ (feijão) 21.

O QUADA versão 3 é composto por seis refeições diárias (café da manhã, lanche da manhã, almoço, lanche da tarde, jantar e lanche da noite ou ceia), e cada uma contém representações gráficas referentes a 23 grupos alimentares. Este instrumento permite a identificação do consumo de alimentos num único dia, em que se observou a ingestão de frutas e hortaliças pelos escolares no dia anterior à coleta de dados 20 .

O questionário alimentar foi aplicado em uma sala de aula específica para a coleta, na forma de um exercício orientado por um dos pesquisadores, contando com a presença de toda a equipe para auxiliar os escolares, quando necessário. A equipe apresentou a importância e objetivo da pesquisa, orientando os alunos a respeito do preenchimento do questionário, ressaltando que as respostas corresponderiam ao consumo do dia anterior e que as frutas e hortaliças poderiam estar inclusas em algumas preparações, como sopas, devendo, neste caso, ser marcadas.

Para a apresentação do questionário, foram elaborados quatro pôsteres $(90 \times 120 \mathrm{~cm})$, contendo cada um duas refeições, idênticas às do questionário disponibilizado às crianças. Em cada uma das refeições apresentadas no pôster, o pesquisador relembrava todos os alimentos presentes e os possíveis horários de realização daquela refeição. Caso o escolar não tivesse realizado alguma refeição, deveria deixar em branco a parte referente a ela, sem assinalar alimentos. Com a finalidade de preservar a qualidade das informações e não interferir nas respostas dos colegas, os escolares foram orientados a não responderem oralmente o questionário.

Com relação às guloseimas, foi observado o consumo de doces e refrigerantes nas refeições durante o dia anterior. A análise de o que os escolares consumiram adequadamente baseou-se nas recomendações do Guia da Pirâmide Alimentar Brasileira ${ }^{12}$ para doces, que sugere o consumo máximo de duas porções ao dia.

O ponto de corte considerado adequado para horas de TV e computador/videogame foi o recomendado pela American Academy of Pediatrics 24 , de duas horas ou menos por dia para crianças e adolescentes.

\section{Variável dependente}

A variável dependente (desfecho) foi o consumo adequado de frutas e hortaliças, analisada por meio da frequência em número de vezes de consumo no dia anterior à entrevista. Considerou-se, no grupo de hortaliças, a ingestão de verduras, legumes e sopa de legumes. O consumo foi considerado adequado quando obteve frequência maior que ou igual a cinco vezes no dia, conforme recomendações da OMS 3.

\section{Análises}

Os dados foram processados no Microsoft Office Excel (Microsoft Corp., Estados Unidos), e as análises foram realizadas nos softwares Epi Info, versão 3.5.1 (Centers for Disease Control and Prevention, Atlanta, Estados Unidos) e Stata 11.0 (Stata Corp., College Station, Estados Unidos). Foi utilizada estatística descritiva (frequência, média e desvio-padrão) e aplicada análise univariada para selecionar as variáveis independentes associadas ao desfecho.

As variáveis que obtiveram valor de $\mathrm{p} \leq 0,20$ foram incluídas no modelo de regressão multivariada de Poisson. Os resultados são apresentados pelas razões de prevalência (RP) e respectivos intervalos de $95 \%$ de confiança. As análises de associação foram estratificadas por sexo, e considerou-se uma significância de 5\%, ou seja, p < 0,05.

$\mathrm{O}$ projeto de pesquisa foi aprovado pelo Comitê de Ética em Pesquisa da Universidade Federal de Santa Catarina (parecer no. 031/06 de 24/ Abr/2006), segundo normas do Conselho Nacional de Saúde sobre pesquisa envolvendo seres humanos (Resoluções no. 196/96 e nº. 251/97).

\section{Resultados}

Este estudo contou com a participação de 4.964 escolares com idade entre 6-10 anos, matriculados entre o segundo e o quinto anos do Ensino Fundamental. Foram excluídos da amostra final 275 escolares, ausentes no dia da coleta dos dados antropométricos; 358 com idade acima dos 10 anos e 89 por inconsistência nos dados.

As características gerais da amostra podem ser visualizadas na Tabela 1. A média de idade encontrada foi de 8,8 anos. A média de consumo de frutas e hortaliças foi de 1,5 vez/dia e a média de consumo de doces, 2,0 vezes/dia. O estado nutricional dos escolares segundo o IMC apresentou média de $17,3 \mathrm{~kg} / \mathrm{m}^{2}( \pm 2,79)$.

A maioria dos escolares era do sexo feminino $(52,2 \%)$, com idade igual ou inferior a oito anos (53\%); residiam no litoral $(50,6 \%)$, encontravam- 
Distribuição dos valores de medidas de tendência central e de dispersão para as variáveis demográficas, de consumo alimentar, comportamentais e antropométricas, em escolares de 6-10 anos de idade $(n=4.964)$ do Estado de Santa Catarina, Brasil, 2007.

\begin{tabular}{lcc}
\hline Variáveis estudadas & Média & DP \\
\hline Idade (anos) & 8,8 & 1,13 \\
Consumo de frutas (vezes/dia) & 0,8 & 1,03 \\
Consumo de hortaliças (vezes/dia) & 0,8 & 0,83 \\
Consumo de frutas e hortaliças (vezes/dia) & 1,5 & 1,33 \\
Consumo de doces (vezes/dia) & 2,0 & 1,41 \\
Horas de TV & 2,3 & 1,30 \\
Horas de computador/videogame & 2,6 & 2,43 \\
IMC (kg/m²) & 17,3 & 2,79 \\
\hline
\end{tabular}

DP: desvio-padrão; IMC: índice de massa corporal.

se matriculados em escolas públicas $(79,1 \%)$, eram filhos de mães $(51,5 \%)$ e pais $(51,7 \%)$ com escolaridade igual ou inferior a oito anos de estudo; eram eutróficos $(78,5 \%)$, consumiam guloseimas em quantidade igual ou inferior a duas vezes ao dia $(66,8 \%)$ e assistiam à TV $(60,8 \%)$ e utilizavam computador/videogame $(86,1 \%)$ por tempo igual ou inferior a duas horas por semana (Tabela 2).

O consumo adequado ( $\geq 5$ vezes no dia) de frutas e hortaliças pelos escolares foi de $2,7 \%$ ( $n=1.33)$, enquanto que $26,6 \%(n=1.319)$ não consumiram estes alimentos nenhuma vez no dia. A omissão de consumo de frutas $(48,1 \%$, $\mathrm{n}=2.390)$ foi semelhante a de hortaliças $(46,3 \%$, $\mathrm{n}=2.300$ ) (Dados não apresentados em Tabelas).

Considerando o total da amostra estudada, verificou-se que as variáveis significativamente associadas com o consumo adequado de frutas e hortaliças foram a região e o consumo de guloseimas. Assim, a prevalência do consumo adequado de frutas e hortaliças foi maior em escolares residentes na região oeste de Santa Catarina e entre aqueles que consumiam uma quantidade de guloseimas igual a ou maior que duas vezes ao dia.

$\mathrm{Na}$ análise estratificada por sexo, somente a variável região associou-se ao consumo adequado de frutas e hortaliças, entre os meninos, enquanto, entre as meninas, as variáveis associadas foram a região e o consumo de guloseimas. $\mathrm{O}$ estado nutricional segundo o IMC mostrou significância limítrofe (Tabela 2).

$\mathrm{Na}$ análise multivariada para a amostra total, as variáveis que se mantiveram associadas ao desfecho foram a região e o consumo de guloseimas. Entre as meninas, estas variáveis foram a região, o IMC e o consumo de guloseimas. Dessa forma, o consumo adequado de frutas e hortaliças foi mais prevalente entre as alunas eutróficas, da região oeste, que consumiam guloseimas mais de duas vezes ao dia (Tabela 3 ).

\section{Discussão}

Como observado nos resultados, apenas 2,7\% dos escolares avaliados apresentaram consumo adequado de frutas e hortaliças ( $>5$ vezes ao dia), enquanto $26,6 \%$ não chegaram a consumir esses alimentos sequer uma vez por dia. Além disso, foi possível observar que, para os meninos, somente a região obteve associação com consumo adequado de frutas e hortaliças; para as meninas, este consumo apresentou-se maior nas eutróficas e naquelas que obtiveram consumo de guloseimas maior que duas vezes ao dia. De modo geral, somente o consumo de guloseimas e a região mantiveram-se associados ao consumo adequado de frutas e hortaliças.

Os dados referentes ao consumo adequado de frutas e hortaliças são preocupantes. Indicam a necessidade não somente de elaboração, mas também de reavaliação de estratégias e ações com foco na alimentação escolar, especialmente no contexto de ações de promoção de saúde, tendo em vista o baixo consumo de frutas e hortaliças na população 25 .

Alguns estudos internacionais têm apontado para o insuficiente consumo de frutas e hortaliças na população escolar. Dentre estes, destacase o de Roseman et al. 26 , que avaliaram a ingestão de alimentos durante sete dias consecutivos em crianças norte-americanas de 7-12 anos, por meio de um questionário autoaplicável de 
Tabela 2

Distribuição do consumo adequado de frutas e hortaliças e associação com as variáveis independentes, em escolares de 6-10 anos de idade do Estado de Santa Catarina, Brasil, 2007.

\begin{tabular}{|c|c|c|c|c|c|c|c|}
\hline \multirow[t]{2}{*}{ Variáveis } & \multicolumn{7}{|c|}{ Consumo adequado de frutas e hortaliças (\%) } \\
\hline & $\begin{array}{l}\text { Distribuição amostral } \\
\text { (\%) total }\end{array}$ & Meninos & Valor de p & Meninas & Valor de p & Total & Valor de $p$ \\
\hline Idade (anos) & & & 0,582 & & 0,536 & & 0,792 \\
\hline$\leq 8$ & 53,0 & 1,7 & & 3,4 & & 2,6 & \\
\hline$>8$ & 47,0 & 1,4 & & 3,9 & & 2,7 & \\
\hline Região & & & 0,025 & & 0,038 & & 0,003 \\
\hline Oeste & 15,3 & 3,1 & & 6,0 & & 4,6 & \\
\hline Centro & 34,1 & 1,6 & & 3,2 & & 2,4 & \\
\hline Litoral & 50,6 & 1,2 & & 3,2 & & 2,3 & \\
\hline Dependência administrativa & & & 0,642 & & 0,315 & & 0,262 \\
\hline Pública & 79,1 & 1,5 & & 3,5 & & 2,5 & \\
\hline Privada & 20,9 & 1,8 & & 4,4 & & 3,2 & \\
\hline $\begin{array}{l}\text { Escolaridade materna (anos de } \\
\text { estudo)* }\end{array}$ & & & 0,881 & & 0,802 & & 0,839 \\
\hline$\leq 8$ & 51,5 & 1,6 & & 3,7 & & 2,6 & \\
\hline$>8$ & 48,5 & 1,6 & & 3,5 & & 2,6 & \\
\hline $\begin{array}{l}\text { Escolaridade paterna (anos de } \\
\text { estudo) ** }\end{array}$ & & & 0,854 & & 0,572 & & 0,549 \\
\hline$\leq 8$ & 51,7 & 1,5 & & 3,7 & & 2,6 & \\
\hline$>8$ & 48,3 & 1,7 & & 4,1 & & 3,0 & \\
\hline IMC dos escolares $\left(\mathrm{kg} / \mathrm{m}^{2}\right)$ & & & 0,639 & & 0,057 & & 0,175 \\
\hline Eutrofia & 78,5 & 1,6 & & 3,4 & & 2,5 & \\
\hline Excesso de peso & 21,5 & 1,5 & & 5,5 & & 3,3 & \\
\hline Consumo de guloseimas (vezes/dia) & & & 0,272 & & 0,005 & & 0,004 \\
\hline$\leq 2$ & 66,8 & 1,4 & & 3,1 & & 2,2 & \\
\hline$>2$ & 33,2 & 2,0 & & 5,6 & & 3,6 & \\
\hline 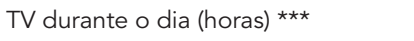 & & & 0,878 & & 0,478 & & 0,634 \\
\hline$\leq 2$ & 60,8 & 1,4 & & 4,1 & & 2,8 & \\
\hline$>2$ & 39,2 & 2,9 & & 3,6 & & 2,6 & \\
\hline $\begin{array}{l}\text { Computador/videogame durante o } \\
\text { dia (horas) \# }\end{array}$ & & & 0,347 & & 0,777 & & 0,866 \\
\hline$\leq 2$ & 86,5 & 1,9 & & 3,9 & & 2,7 & \\
\hline$>2$ & 13,5 & 2,8 & & 2,7 & & 2,4 & \\
\hline
\end{tabular}

IMC: índice de massa corporal.

${ }^{\star} \mathrm{n}=4.375$;

** $\mathrm{n}=3.985$;

$\star \star \star ~ n=4.736$;

$\# \mathrm{n}=4.736$.

comportamento alimentar. Os autores encontraram somente $30 \%$ de crianças com consumo de frutas pelo menos uma vez ao dia.

No México, estudo realizado por Pérez-Lizaur et al. 27, por intermédio do método recordatório alimentar de 24 horas de dois dias, apontou $11 \%$ das crianças de 7-10 anos com consumo de frutas igual ou maior do que três vezes ao dia. Na República Checa, Jakubikova et al. 28 , utilizando o mé- todo recordatório alimentar de 24 horas, aplicado em dois dias consecutivos, encontraram $22 \%$ das crianças com consumo diário de frutas e hortaliças igual ou superior a cinco porções por dia.

Com relação aos estudos nacionais, uma análise dos dados da PeNSE, baseada na avaliação da frequência de consumo de oito alimentos, grupos de alimentos ou preparações, apontou que $21 \%$ dos escolares não consumiam frutas e 
Análise de regressão de Poisson entre o consumo adequado de frutas e hortaliças e as variáveis independentes, em escolares de 6-10 anos de idade do Estado de Santa Catarina, Brasil, 2007.

\begin{tabular}{|c|c|c|c|c|}
\hline \multirow[t]{2}{*}{ Variáveis } & \multicolumn{2}{|c|}{ Meninas } & \multicolumn{2}{|c|}{ Total } \\
\hline & RP bruta (IC95\%) & RP ajustada (IC95\%) * & RP bruta (IC95\%) & RP ajustada (IC95\%) * \\
\hline \multicolumn{5}{|l|}{ Região } \\
\hline Oeste & 1,00 & 1,00 & 1,00 & 1,00 \\
\hline Centro & $0,76(0,6 ; 1,0)$ & $0,73(0,6 ; 1,0)$ & $0,72(0,6 ; 0,9)$ & $0,69(0,6 ; 0,9)$ \\
\hline Litoral & $0,62(0,4 ; 0,7)$ & $0,61(0,4 ; 0,7)$ & $0,51(0,4 ; 0,7)$ & $0,46(0,3 ; 0,7)$ \\
\hline Valor de $\mathrm{p}$ & 0,038 & 0,018 & 0,003 & 0,001 \\
\hline \multicolumn{5}{|c|}{ IMC dos escolares $\left(\mathrm{kg} / \mathrm{m}^{2}\right)$} \\
\hline Excesso de peso & 1,00 & 1,00 & 1,00 & 1,00 \\
\hline Eutrofia & $1,54(1,0 ; 2,4)$ & $1,59(1,0 ; 2,5)$ & $1,31(0,9 ; 1,9)$ & $1,34(0,9 ; 2,0)$ \\
\hline Valor de p & 0,057 & 0,039 & 0,175 & 0,142 \\
\hline \multicolumn{5}{|c|}{ Consumo de guloseimas (vezes/dia) } \\
\hline$\leq 2$ & 1,00 & 1,00 & 1,00 & 1,00 \\
\hline$>2$ & $1,77(1,2 ; 2,3)$ & $1,92(1,3 ; 2,9)$ & $1,66(1,2 ; 2,3)$ & $1,78(1,3 ; 2,5)$ \\
\hline Valor de $p$ & 0,005 & 0,002 & 0,004 & 0,001 \\
\hline
\end{tabular}

IC95\%: intervalo de 95\% de confiança; IMC: índice de massa corporal; RP: razão de prevalência.

* As variáveis foram ajustadas entre si.

$26,8 \%$ não consumiam hortaliças nenhum dia na semana 29 .

Nunes et al. 11, ao investigarem o consumo alimentar de adolescentes durante cinco dias úteis, por meio de um questionário específico da pesquisa, encontraram somente $4,5 \%$ dos investigados com consumo diário de frutas. Toral et al. 30, ao avaliarem adolescentes de 10-17 anos em Piracicaba, São Paulo, mediante questionário contendo perguntas fechadas a respeito do consumo de frutas, hortaliças e sucos, detectaram que $28 \%$ desses jovens consumiam menos de três porções de frutas e hortaliças por dia.

No Município de Camboriú, Estado de Santa Catarina, Grillo et al. 31 avaliaram crianças de 5-12 anos, com aplicação de um questionário de frequência alimentar. $\mathrm{O}$ estudo concluiu que somente $12 \%$ delas consumiam vegetais, e $40 \%$ consumiam frutas em quantidades adequadas.

Fiates et al. 13, ao investigarem escolares de 7-10 anos em Florianópolis, por meio da aplicação de um questionário semiestruturado com perguntas abertas e fechadas, encontraram médias semanais de consumo de frutas/suco natural de 4,7 porções/dia e de verduras, de 3,6 porções / dia. Em adição, foi observado que as crianças levavam sete dias para consumir a recomendação de frutas e hortaliças de um dia.

Outro estudo realizado em Florianópolis, que avaliou o consumo alimentar de escolares por meio do QUADA, encontrou consumo adequado de frutas e hortaliças ( $\geq 5$ vezes ao dia) em $15 \%$ dos escolares avaliados. No entanto, ao analisar separadamente os grupos de frutas e hortaliças, verificou que o consumo satisfatório de frutas, de três ou mais porções ao dia, foi maior $(27,2 \%)$ que o de hortaliças $(5,5 \%)$, de duas ou mais porções ao dia 14 .

Os resultados das pesquisas apresentadas não são diretamente comparáveis com os do presente estudo, por tratarem de faixas etárias diferentes e terem adotado diversos métodos de avaliação de consumo alimentar. No entanto, tais investigações apontam para a alta prevalência de baixo consumo de frutas e hortaliças entre crianças e adolescentes, o que pode indicar uma situação desfavorável para a saúde dessa população.

Com relação aos fatores associados ao consumo de frutas e hortaliças, o presente estudo aponta diferenças relacionadas ao sexo dos escolares, pois o consumo alimentar das meninas foi associado com o estado nutricional e consumo de guloseimas, ao passo que o dos meninos, o foi com a região geográfica. Este resultado revela o maior consumo de guloseimas entre as meninas e pode estar relacionado ao maior consumo de frutas e hortaliças. Resultado semelhante foi encontrado por Costa et al. ${ }^{32}$, que identificaram que meninas adolescentes de Toledo consumiam mais alimentos dos grupos das hortaliças e dos açúcares e doces do que os meninos.

A relação do maior consumo de doces com o maior consumo de frutas e hortaliças pode ser atribuída à prática de alguns pais, de negociação ou 
compensação alimentar de doces ou sobremesas, condicionados ao consumo de hortaliças e frutas pelas crianças, na refeição. Tal prática foi descrita por Casotti 33 ao comentar a forma como os adultos ensinam as crianças a comer, recompensando-as por comerem o que faz bem, por meio do que faz mal. A "comida do mal" (guloseimas) não é dada às crianças se a "comida do bem" (frutas e hortaliças) não for ingerida.

É importante ressaltar ainda que, na análise multivariada da amostra total, somente o consumo de doces e a região permaneceram associados ao consumo adequado de frutas e hortaliças. Além disso, entre os escolares, o consumo de guloseimas (média de duas vezes ao dia) ocorreu com maior frequência do que o consumo de frutas e hortaliças (média de 1,5 vez ao dia).

O elevado consumo de doces por escolares também foi encontrado em outros estudos nacionais, como o realizado por Carmo et al. 34 , que encontraram média de 3,8 porções por dia de consumo de doces. Pesquisa realizada por Nunes et al. 11 encontrou frequência diária de consumo de doces em $34,5 \%$ dos adolescentes avaliados. Dados provenientes de estudos realizados na cidade de Florianópolis apontam que 43,6\% dos escolares consomem guloseimas cinco ou mais dias na semana 9 e que, para $78,7 \%$, o consumo é diário 14 .

Esses resultados indicam a necessidade de implementação de estratégias educativas nas escolas, com ênfase na redução de consumo de doces e na importância de uma alimentação saudável, principalmente entre as meninas.

A influência da localização geográfica (região oeste de Santa Catarina) na frequência mais elevada do consumo de frutas e hortaliças entre os escolares do sexo masculino pode ser atribuída ao fato de essa área ter sua atividade econômica baseada na agroindústria, o que pode facilitar o acesso a esses alimentos pelos escolares. Enquanto o meio-oeste é forte na criação de bovinos e produção de maçã, o oeste é considerado o "celeiro" de Santa Catarina, onde é produzida boa parte de grãos, aves e suínos 35 . Sendo assim, essa região apresenta características do meio rural.

No estudo de revisão de Rasmussem et al. ${ }^{36}$, foram encontrados quatro artigos que investigaram a influência da urbanização no consumo de frutas e hortaliças. Destes, três deles identificaram que o consumo de frutas e/ou vegetais foi mais frequente entre as crianças e adolescentes do meio rural.

O presente estudo apresenta como limitação a utilização de indicador de adequação do consumo de frutas e hortaliças, definido como consumo diário igual ou maior a cinco vezes ao dia. Porém, as recomendações de consumo desses alimentos 6,7 consideram o número de porções consumidas ao dia em gramas. Esta diferença na medida pode ter levado à subestimação do consumo de frutas e hortaliças pelos escolares. Ainda assim, a adoção do indicador "frequência de consumo em número de vezes ao dia" de frutas e hortaliças é bastante comum na literatura mundial 25,37,38,39,40,41.

Em um estudo de abrangência nacional, que utilizou o sistema Vigilância de Fatores de Risco e Proteção para Doenças Crônicas por Inquérito Telefônico (VIGITEL), com indicador de consumo de frutas e hortaliças semelhante ao do presente trabalho, a validade dos indicadores de consumo de alimentos e bebidas apontou, para consumo de frutas e hortaliças, reprodutibilidade moderada (coeficiente kappa $=0,57$ ), sensibilidade de $46,4 \%$ e especificidade de $71,6 \%$, tendo como referência a classificação dos indivíduos com base em três inquéritos recordatórios alimentares de 24 horas 42 .

Outra possível limitação do estudo está relacionada ao cálculo do tamanho da amostra, uma vez que este foi realizado somente para o estudo de prevalência, não para testar associações. No entanto, considerando o tamanho de amostra disponível ( $\mathrm{N}=4.242$ ), as prevalências das distintas variáveis de exposição e do desfecho (consumo adequado de frutas e hortaliças), assim como o ajuste para fatores de confusão, o presente estudo teve poder de $80 \%$ para detectar como estatisticamente significativas $(\mathrm{p}<0,05)$ RP entre 1,7 e 1,8 para a maioria das variáveis. As exceções foram a dependência administrativa e o tempo de uso de computador/videogame, para as quais o tamanho de amostra permitiria detectar como significativas RP de 2,0 e 2,3, respectivamente.

Mais uma limitação a ser considerada é a ausência de dados de consumo alimentar e estado nutricional dos pais nas análises de associação. Esses dados podem revelar os hábitos alimentares mantidos nos domicílios dos escolares, apresentando-se como fatores determinantes para o consumo adequado de frutas e hortaliças.

Há necessidade de mais pesquisas para avaliar o consumo de frutas e hortaliças pelos escolares, não só por meio das porções consumidas, como também pelos dados nutricionais dos pais. Desse modo, será possível contribuir para a orientação de políticas locais de saúde que visem ao aumento do consumo desses alimentos, bem como de pesquisas de avaliação do impacto de programas já estabelecidos na alimentação dos escolares. 


\section{Resumo}

Objetivou-se estimar a frequência do consumo adequado de frutas e hortaliças e identificar os fatores associados em escolares do Estado de Santa Catarina, Brasil. Trata-se de estudo transversal, realizado com 4.964 escolares de escolas públicas e privadas de oito municípios do estado. Foram analisadas variáveis sociodemográficas, comportamentais, antropométricas e de consumo alimentar. A ingestão de frutas e hortaliças cinco ou mais vezes ao dia foi considerado o consumo adequado. Para testar a associação entre o consumo adequado de frutas e hortaliças e as variáveis independentes, foi utilizada a regressão multivariada de Poisson, considerando o nível de significância de 5\% $(p \leq 0,05)$. O consumo adequado esteve presente em $2,7 \%$ dos escolares, enquanto $26,6 \%$ não consumiram frutas e hortaliças sequer uma vez por dia. Somente o consumo de guloseimas manteve-se diretamente associado ao consumo adequado de frutas e hortaliças. Os dados apontam a necessidade de estratégias específicas para o ambiente escolar, a fim de promover o maior consumo de frutas e hortaliças nessa população.

Consumo de Alimentos; Alimentação Escolar; Frutas; Verduras

\section{Colaboradores}

L. C. F. Costa se responsabilizou pela análise e interpretação dos resultados e redação do manuscrito. F. A. G. Vasconcelos se responsabilizou pela concepção da pesquisa, estruturação e revisão crítica do manuscrito. A. C. T. Corso se responsabilizou pela concepção da pesquisa, estruturação e revisão crítica do manuscrito.

\section{Agradecimentos}

Agradecemos ao CNPq (processo $\mathrm{n}^{\circ}$. 402334/2005-1) por ter possibilitado e financiado esta pesquisa.

\section{Referências}

1. Steinmetz KA, Potter JD. Vegetables, fruit, and cancer prevention: a review. J Am Diet Assoc 1996; 96:1027-39.

2. Ness AR, Powles JW. Fruit and vegetables, and cardiovascular disease: a review. Int J Epidemiol 1997; 26:1-13.

3. World Health Organization. Diet, nutrition and the prevention of chronic diseases. Geneva: World Health Organization; 2003. (Report of a Joint WHO/ FAO Expert Consultation).

4. Enes CC, Slater B. Obesidade na adolescência e seus principais fatores determinantes. Rev Bras Epidemiol 2010; 13:163-71.

5. Instituto Brasileiro de Geografia e Estatística. Pesquisa de Orçamentos Familiares 2008-2009: antropometria e estado nutricional de crianças, adolescentes e adultos no Brasil. Rio de Janeiro: Instituto Brasileiro de Geografia e Estatística; 2010.

6. World Health Organization. Diet, nutrition and the prevention of chronic diseases. Geneva: World Health Organization; 2002. (WHO Technical Report Series, 916),
7. Secretaria de Atenção à Saúde, Ministério da Saúde. Guia alimentar para a população brasileira: promovendo a alimentação saudável. Brasília: Ministério da Saúde; 2006.

8. Instituto Brasileiro de Geografia e Estatística. Pesquisa de Orçamentos Familiares 2008-2009: análise do consumo alimentar pessoal no Brasil. Rio de Janeiro: Instituto Brasileiro de Geografia e Estatística; 2010.

9. Instituto Brasileiro de Geografia e Estatística. Pesquisa Nacional de Saúde do Escolar 2009. Brasília: Instituto Brasileiro de Geografia e Estatística; 2009.

10. Toral N, Slater B, Cintra IP, Fisberg M. Comportamento alimentar de adolescentes em relação ao consumo de frutas e verduras. Rev Nutr 2006; 19 : 2-12.

11. Nunes MMA, Figueiro JN, Alves JGB. Excesso de peso, atividade física e hábitos alimentares entre adolescentes de diferentes classes econômicas em Campina Grande (PB). Rev Assoc Med Bras (1992) 2007; 53:130-4. 
12. Philippi ST, Latterza AR, Cruz ATR, Ribeiro LC. Pirâmide alimentar adaptada: guia para escolha dos alimentos. Rev Nutr 1999; 12:65-80.

13. Fiates GMR, Amboni RDMC, Teixeira E. Comportamento consumidor, hábitos alimentares e consumo de televisão por escolares de Florianópolis. Rev Nutr 2008; 21:105-14.

14. Assis MAA, Calvo MCM, Kupek E, Vasconcelos FAG, Campos VC, Machado M, et al. Qualitative analysis of the diet of a probabilistic sample of schoolchildren from Florianopolis, Santa Catarina State, Brazil, using the Previus Day Food Questionnarie. Cad Saúde Pública 2010; 26:1355-65.

15. Ministério da Saúde. Guia alimentar para a população brasileira. http://www.saude.gov.br (acessado em 25/Ago/2009).

16. Ricardo GD, Caldeira GV, Corso ACT. Prevalência de sobrepeso e obesidade e indicadores de adiposidade central em escolares de Santa Catarina, Brasil. Rev Bras Epidemiol 2009; 12:424-35.

17. Gabriel CG, Vasconcelos FAG, Andrade DF, Schmitz BAS. First Law regulating school canteens in Brazil: evaluation after seven years of implementation. Arch Latinoam Nutr 2009; 59:128-38.

18. Lohman TG, Roche AF, Martorell R. Anthropometric standardization reference manual. Champaign: Human Kinetics Books; 1991.

19. Cole TJ, Bellizi MC, Flegal KM, Dietz WH. Establishing a standard definition for child overweight and obesity worldwide: internacional survey. BMJ 2000; 320:1240-3.

20. Assis MAA, Beneder J, Kerpel R, Vasconcelos FAG, Pietro PFD, Kupek E. Validação da terceira versão do Questionário Alimentar do Dia Anterior (QUADA-3) para escolares de 6 a 11 anos. Cad Saúde Pública 2009; 25:1816-26.

21. Assis MAA, Guimarães D, Calvo MCM, Barros MVG, Kupek E. Reprodutibilidade e validade de questionário de consumo alimentar para escolares. Rev Saúde Pública 2007; 41:1054-7.

22. Barros MV, Assis MAA, Pires MC, Grossemann S, Vasconcelos FAG, Luna MEP, et al. Validity of physical activity and food consumption questionnaire for children aged seven to ten years old. Rev Bras Saúde Matern Infant 2007; 7:437-48.

23. Lobo AS, Assis MAA, Barros MVG, Calvo MCM, Freitas SFT. Reprodutibilidade de um questionário de consumo alimentar para crianças em idade escolar. Rev Bras Saúde Matern Infant 2008; 8:55-63.

24. American Academy of Pediatrics. Children, adolescents and television. Pediatrics 2001; 107:423-6.

25. Jaime PC, Figueiredo ICR, Moura EC, Malta DC. Fatores associados ao consumo de frutas e hortaliças no Brasil, 2006. Rev Saúde Pública 2009; 43 Suppl 2:57-64.

26. Roseman MG, Yeung WK, Nickelsen J. Examination of weight status and dietary behaviors of middle school students in Kentucky. J Am Diet Assoc 2007; 107:1139-45.

27. Pérez-Lizaur AB, Kaufer-Horwitz M, Plazas M. Environmental and personal correlates of fruit and vegetables consumption in low income, urban Mexican children. J Hum Nutr Diet 2008; 21:63-71.

28. Jakubikova M, Dofkova M, Ruprich J. Fruit and vegetable intake in the Czech child population. Public Health Nutr 2011; 14:1047-54.
29. Levy RB, Castro IRR, Cardoso LO, Tavares LF, Sardinha LMV, Gomes FS, et al. Consumo e comportamento alimentar entre adolescentes brasileiros: Pesquisa Nacional de Saúde do Escolar (PeNSE), 2009. Ciênc Saúde Coletiva 2010; 15 Suppl 2: 3085-97.

30. Toral N, Slater B, Silva MV. Consumo alimentar e excesso de peso de adolescentes de Piracicaba, São Paulo. Rev Nutr 2007; 20:449-59.

31. Grillo LP, Klitzke A, Campos IC, Mezadri T. Riscos nutricionais de escolares pertencentes a famílias de baixa renda do litoral catarinense. Texto \& Contexto Enferm 2005; 14 Esp: 17-23.

32. Costa MCD, Júnior LC, Matsuo T. Hábito alimentar de escolares adolescentes de um município do oeste do Paraná. Rev Nutr 2007; 20:461-71.

33. Casotti L. À mesa com a família: um estudo do comportamento do consumidor de alimentos. Rio de Janeiro: Mauad; 2002.

34. Carmo MB, Toral N, Silva MV, Slater B. Consumo de doces, refrigerantes e bebidas com adição de açúcar entre adolescentes da rede pública de ensino de Piracicaba, São Paulo. Rev Bras Epidemiol 2006; 9:121-30.

35. Governo do Estado de Santa Catarina. Santa Catarina: os jeitos da Terra. http://www.sc.gov.br/ (acessado em 17/Abr/2011).

36. Rasmussen M, Krolner R, Klepp KI, Lytler L, Brug J, Bere E, et al. Determinants of fruit and vegetable consumption among children and adolescents: a review of the literature. Part I: quantitative studies. Int J Behav Nutr Phys Act 2006; 3:22.

37. Wandel M. Dietary intake of fruits and vegetables in Norway: influence of life phase and socioeconomic factors. Int J Food Sci Nutr 1995; 46: 291-301.

38. Bazzano LA, He J, Ogden LG, Loria CM, Vupputuri S, Myers L, et al. Fruit and vegetable intake and risk of cardiovascular disease in US adults: the first National Health and Nutrition Examination Survey Epidemiologic Follow-up Study. Am J Clin Nutr 2002; 76:93-9.

39. Serdula MK, Gillespie C, Kettel-Khan L, Farris R, Seymour J, Denny C. Trends in fruit and vegetable consumption among adults in the United States: behavioral risk factor surveillance system, 19942000. Am J Public Health 2004; 94:1014-8.

40. Blanck HM, Gillespie C, Kimmons JE, Seymour JD, Serdula MK. Trends in fruits and vegetable consumption among U.S. men and women, 19942005. Prev Chronic Dis 2008; 5:A35.

41. Prättälä R, Paalanen L, Grinberga D, Helasoja V, Kasmel A, Petkeviciene J. Gender differences in the consumption of meat, fruit and vegetables are similar in Finland and Baltic countries. Eur J Public Health 2007; 17:520-5.

42. Monteiro CA, Moura EC, Jaime PC, Claro RM. Validade de indicadores do consumo de alimentos e bebidas obtidos por inquérito telefônico. Rev Saúde Pública 2008; 42:582-9.

Recebido em 23/Ago/2011

Versão final reapresentada em 15/Fev/2012 Aprovado em 02/Mar/2012 